\section{Questión}

Periodismo / Comunicación ISSN 1669-6581
- Av. $44 \mathrm{~N}^{\circ} 676,1^{\circ}$ piso

CP 1900 - La Plata - Argentina

www.perio.unlp.edu.ar/question

Disparates, desatinos y preguntas en cuarentena

José Manuel López Romero

https://doi.org/10.24215/16696581e366

\title{
Disparates, desatinos y preguntas en cuarentena
}

\section{Nonsense, nonsense and questions in quarantine}

\begin{abstract}
José Manuel López Romero Estudiante del doctorado en Ciencias Sociales de la Universidad Autónoma Metropolitana Xochimilco (México) y Maestro en comunicación por la Universidad de Guadalajara. Ha sido profesor universitario y publicado artículos y capítulos de libro sobre los consumos culturales de los jóvenes. cronos2000x@hotmail.com
\end{abstract}

\section{Resumen}

Las narrativas de la pandemia son las narrativas que ya existían y se engarzan con nuestros imaginarios, pero también con nuestras filias y fobias para atizar nuestros odios e intereses, respecto, por ejemplo, a la actuación de los gobiernos, pero también respecto a los otros, los vecinos, los ricos, los pobres, los chinos, los suecos...Las referencias a la literatura y el cine han sido inevitables en sus referencias a las distopías futuristas que todos hemos evocado, pero también en la elección de las imágenes que ha hecho la prensa para realizar su coberturas, privilegiando los planos abiertos de las ciudades abandonadas y la omnipresencia de las máscaras, los cubrebocas y, de ser posible, los trajes completos de médicos, enfermeras y los cuerpos de desinfección (en México les han llamado cazafantasmas) encargados de calles y lugares públicos

\section{Palabras Clave \\ Narrativas - Realidad - Tecnología}

\section{Summary}


The narratives of the pandemic are the narratives that already existed and are set with our imaginaries, but also with our philiates and phobias to ty up our hatreds and interests, regarding, for example, the actions of governments, but also with respect to others, neighbors, the rich, the poor, the Chinese, the Swedes... References to literature and film have been unavoidable in its references to the futuristic dystopias that we have all evoked, but also in the choice of images that the press has made to make its coverage, privileging the open plans of abandoned cities and the omnipresence of masks, the head covers and, if possible, the full costumes of doctors, nurses and disinfection bodies (in Mexico have called them ghostbusters) in charge of streets and public places

\section{Key Words}

Narratives - Reality - Technology

La vida no ha cambiado mucho para mí, salvo por el contenido de las noticias y los memes. Han desaparecido algunos referentes comunes en ellos y se ha dado la adecuación de todo lo demás (de todo lo que sobrevive) a la lógica de la pandemia. A cambio, la vida de casi todos ha dado un vuelco hacia adentro, cuando no hacía peores destinos.

En medio de estas fracturas y desconciertos pandémicos del tecnoconfinamiento (si se puede acceder a él) o la terrible realidad pelona y apocalíptica, si se es uno de los trabajadores imprescindibles llamados esenciales para seguir haciendo posibles los encierros de otros, hay un destino peor que el de ser esencial o imprescindible y es el de los prescindibles. Si tus servicios no son requeridos y no debes estar en la calle, si te dedicas a la venta informal en las salidas del metro o el mercado itinerante, si tienes un pequeño negocio no esencial, si no tienes un contrato, si no estás en la lista de los programas sociales, si deambulas en el filo de la invisibilidad, estás en esa categoría que no alcanzamos a ver ni a entender, porque nos queda lejos si estamos escribiendo o leyendo esto, si estamos preocupados por los cambios en la industria del entretenimiento o la sobrecarga académica de una escuela que no se adapta, porque no entiende la educación a distancia a la que ha sido arrojada; nos queda lejos si estamos añorando el fin del capitalismo desde nuestros dispositivos electrónicos que siguen nutriendo a los pescadores que están ganando en este río revuelto, si estamos pensando en la "venganza" de la naturaleza y el reajuste necesario del planeta que "nos llama a cuentas", si creemos que 
es la ira de dios "jalando las riendas" de la humanidad pecadora y libertina o si creemos que esto es una gran oportunidad para crear la diferencia y despertarnos en el añorado "después" como mejores seres humanos, sociedades más justas o con entidades supranacionales que funcionen, si viviremos sólo con lo esencial en el "después" que parece alejarse más y más tras los rebrotes y regresos al confinamiento en los lugares que empezaron antes. En todos esos casos, quienes creen en ello, seguro encontrarán evidencia empírica que confirme sus suposiciones en ese hipotético "después". Seguro ya la están encontrando y compartiendo en redes sociales.

En este punto, ya sabemos que no me concentraré. No conseguiré enfocarme y ser estricto. No podré argumentar y concluir. Nunca puedo, pero en este caso, me amparo en el espíritu contradictorio de la pandemia, en la incertidumbre cotidiana del confinamiento. Así parece que sobrevivimos estos tiempos. Así lo veo en las ventanas electrónicas y materiales por las que me asomo al exterior. Estamos añorando el gran cambio y la gran revolución del "después" mientras la rabiosa pelea cotidiana se da por recuperar el "antes" que, igual que su contraparte es idílico e inexistente. Cada día libramos la batalla por la normalidad, por recuperar lo que creímos que teníamos o querríamos haber tenido; por lo que creemos merecer. Queremos que esta normalidad se parezca a la otra, a la de antes, mientras llega el después.

Los siguientes disparates de la cuarentena surgen o desembocan en preguntas, que es lo único que tenemos en estos momentos, ante una situación tan compleja e inédita como, por primera vez, realmente mundial. Lo que sigue no son subtítulos o apartados, sino brotes de la pandemia en forma de pregunta, descripción o pura angustia transcrita y provienen de las noticias, los memes o las conversaciones con las personas que me han ofrecido otros ojos y otros alcances.

\section{Es la guerra y son las guerras que emergen}

Las metáforas bélicas no cesan y, en el borde, aparecen las comparaciones del confinamiento con beneficios de entretenimiento contra la abuela que sobrevivió a los nazis. Estos juegos relajan, pero no alteran el contenido de esta construcción de la cotidianidad, el humor y el periodismo que refieren "la lucha contra", "la resistencia", "los ataques", "la sobrevivencia". El aislamiento se vive como estado de guerra, pero la guerra es contra un ente invisible en el que una buena parte de la población no cree, otra reacciona exageradamente y otros acatan lo indicado y piden más control de propios y ajenos. Cada uno, además, es incapaz de ver o 
entender al otro sin juzgarlo o negarlo. La razón nos asiste, los demás están equivocados ¿Cómo se concilia eso, ¿cómo se ajusta?, ¿cómo se exige, pide o piensa? No lo sé.

Todos estamos bajo el mismo estado de guerra, pero nunca ese todos fue tan todos como el mundo entero.

Lo que las imposiciones generales pasan por alto es una compleja red de diferencias y contraposiciones, de situaciones distintas y contradictorias, de estridencia en twitter, las conspiraciones sin fuente en Whatsapp y el silencio digital de los que no tienen ahí una voz, pero estalla o estallará en las calles.

Cuando compartí una nota sobre la matanza de murciélagos en Perú, los indignados y sorprendidos asomaron la cabeza. Unas semanas después, esos mismos asombrados e indignados querían pasar al cuchillo metafórico de las redes a esos "pinches ricos insensibles" que habían viajado y vuelto al país, que exigían pruebas, que eran escoria. Otros están criticando ácidamente a quienes organizan fiestas o se forman para comprar pizzas para los hijos el día del niño o comida para las madres el 10 de mayo en las zonas más pobres de la ciudad; se multiplican en México los memes sobre el líquido sinovial que está detrás de la ficción pandémica según el engarce en redes de la historia de la irrupción de familiares de fallecidos por covid en un hospital y una vieja y siniestra leyenda urbana. Los ánimos se nos caldean a todos, las ideas se nos revuelven y sacan lo que ya traíamos ahí, escondido, cubierto por la convivencia y la "normalidad".

\section{Morir es solo un número}

Una joven madre sale del hospital en la ciudad donde vivo. El video recorre las venas digitales de mis contactos y aparece días más tarde en algunos noticiarios nacionales durante unos segundos. Es la primera paciente curada aquí. Al salir, relata lo duro del aislamiento y la fuerza que le dio la arenga de una enfermera que le dijo que, si moría, no dejarían a sus hijos verla ni despedirse de su cadáver. Contra ese relato, me cuentan el de otros que, sin morir por causa del virus, sí murieron en sus tiempos y la manera en que esta cuarentena ha afectado los ritos funerarios y el duelo. En algunos lugares con la obligación de cremar (contra la tradición y el deseo de las personas), en otras, la restricción del número de personas que pueden ingresar al cementerio y otras más, en la supresión de los velorios. La practicidad sanitaria y la idea de 
colectividad parece imponerse a la tradición de siglos, a las creencias religiosas a los rituales del duelo, a los deseos personales, a la muerte antes de estas muertes.

Todos los días escuchamos en televisión el número de muertes del día. Cotejamos, comparamos, proyectamos. En México, además, seguimos comparando con el número de muertes por otras causas y por efectos de la delincuencia organizada. Al principio, los analistas usaban los números para desestimar el impacto de la enfermedad en la demografía de los países y para impulsar sus agendas contra las medidas de aislamiento. A la avalancha estadística de muertos reportados, se suman las de las proyecciones por venir y la disputa por la legitimidad de los números y la sospecha del encubrimiento. De un lado, la dimensión humana de la pérdida y del otro, los números que se supone que guían las decisiones que afectan a personas de carne y hueso.

\section{Ciencia ficción y tecnologías reales}

La revolución no pasará por televisión, se está viviendo en trasmedia y, por lo que vemos y tememos, está ocurriendo bajo nuestra piel, o bajo la de aquellos con los dispositivos que pueden hacer eso, porque desde el rezago, miramos. Aunque la revolución no es la esperada por los que la esperan, este golpe seco a la "normalidad" sí que habrá cambiado nuestras formas de relación, a pesar de que intentaremos correr a recuperar el paraíso perdido en el "después" y ahora mismo tratemos de aferrarnos a lo que teníamos. Los grandes flujos económicos ya están empezando a recomponerse, la publicidad y el teletrabajo se adaptan aterradoramente rápido a las circunstancias (Time Doctor o Hubstaff ya existían, pero se extienden ahora como Zoom para la escuela y la familia), los gobiernos ganan cada día más terreno a las libertades y crecen sus facultades policiales con el consentimiento de la mayoría y el beneplácito de algunos, y no parece posible que quieran abandonar esas facultades extraordinarias cuando pase la emergencia 0 que no pase, pero deje de ser emergencia.

De entre los relatos familiares, entresaco las diferentes formas de enseñar y las quejas diferenciadas que esto entraña. La más agobiante de todas y también la menos cuestionada es la obsesión de la foto como prueba en las escuelas y en las noticias compartidas. La imagen como sinónimo de verdad, aunque en sí misma sea una contradicción, pero esa noción persiste y atribula a las madres (son casi siempre ellas, casi nunca ellos) que deben hacer capturas y sobrecargan las redes de datos. Las noticias falsas también se apoyan en la imagen, alterada, 
descontextualizada o simplemente no relacionada con lo que intenta probar, pero ahí está. Siguen funcionando nuestras esas viejas nociones en las nuevas mentiras. Esta coyuntura tecnosanitaria debería darnos pistas para pensar mejor nuestra relación con las mentiras que existían antes y las nuevas mentiras y con las mentiras propias de la emergencia. Como sabemos, cada tecnología que se propone lograr la ilusión de naturalidad, debe para ello, articular mentiras más complejas para lograrlo. Así, la foto a color requiere de más artilugios y caminos tangenciales para mentir de una manera tal que nos de la ilusión de reproducción a color, respecto a las que lo hacían en blanco y negro (presencia ausencia de la luz), las tecnologías digitales refinaron esos artilugios de fantasmagoría basados en rejillas igualmente monocromáticas y ni hablar de la realidad virtual o la realidad aumentada. La relación es la misma, engaños más complejos y elaborados para ser más cercanos, cómodos y naturales. Del mismo modo, la ilusión del contacto, la conversación, lo que siempre hicimos, de lo que siempre hacemos se intenta reproducir con las aplicaciones de videocomunicación y vigilancia. Muchos para que parezca clase en la sala de Zoom, tiempos de atención artificialmente prolongados, fotos, fotos y más fotos para probar que estuvimos en el video y celebración de reuniones virtuales (fiestas de cumpleaños, borracheras, juegos de mesa, tutoriales) con personas con las que hace mucho tiempo que no hablábamos o, de plano, con aquellos que nunca lo habíamos hecho. Hay múltiples memes para comprobar cada uno de los casos anteriores y nuestras propias vidas recientes para certificarlos.

\section{Las historias que nos sobrevivirán}

Las narrativas de la pandemia son las narrativas que ya existían y se engarzan con nuestros imaginarios, pero también con nuestras filias y fobias para atizar nuestros odios e intereses, respecto, por ejemplo, a la actuación de los gobiernos, pero también respecto a los otros, los vecinos, los ricos, los pobres, los chinos, los suecos...

Las referencias a la literatura y el cine han sido inevitables en sus referencias a las distopías futuristas que todos hemos evocado, pero también en la elección de las imágenes que ha hecho la prensa para realizar su coberturas, privilegiando los planos abiertos de las ciudades abandonadas y la omnipresencia de las máscaras, los cubrebocas y, de ser posible, los trajes completos de médicos, enfermeras y los cuerpos de desinfección (en México les han llamado cazafantasmas) encargados de calles y lugares públicos. Ésas referencias familiares han 
resultado al tiempo inquietantes por lo que representan (a veces exagerando con el puro hecho de documentar) y tranquilizadoras porque forman parte del acervo con el que damos sentido al mundo, de algún modo ya lo hemos vivido y superado. Contra esta narrativa, la genial familia de memes que compara a los EEUU en las películas y en las pandemias reales.

Esas narrativas presentes nos habitan y se han estado analizando. Me pregunto cuáles serán las narrativas con las que nos veamos (o nos vean) desde el futuro. ¿Quién será la nueva Dorothea Lange de la postpandemia que retrate la madre de todas las crisis que parece avecinarse? ¿Quién será el Edward Hopper del confinamiento, ahora que ha sido multicitado y referido para proyectarnos, junto con las obras de Munch o Schiele? ¿Cuál serán la historia que como El Decameron consiga adherirse a este suceso para cualquier referencia posterior? ¿Cuáles de las que ahora nos acompañan y explican la cuarentena formarán parte de esa inmensa mayoría que se desvanecerá?

¿Cómo recordaremos las mentiras, pamplinas y paparruchas que buscan dar una explicación única? ¿Recordaremos que siempre nos ha tranquilizado tener una explicación única y poderosa, simple? Las mentiras organizadas son mejor que la incertidumbre del caos, el complot es siempre tranquilizador, porque coloca un villano, un organizador un ganador, es una explicación simple y útil.

Nuestras múltiples ideas actuales de que el futuro es inevitable, sobre lo que pasará o no pasará y cómo habrá de serlo cambiarán seguramente pera tener la misma misión, la misma contundencia y la misma "inevitabilidad" pero después de los hechos, cuando sólo quede una o dos o tres que diluyan las miles que hoy formulamos como inevitables.

\section{No hay salidas ni final y, sin embargo, la vida continúa}

Mientras escribo, Corea, Líbano, Kuwait y Arabia Saudita regresan al confinamiento por rebrotes, sólo república Checa parece seguir con los plantes de abrir. Santiago de Chile cierra las colonias que había abierto. México se prepara para lo que llaman una "nueva normalidad" con la reapertura de ciertos sectores considerados estratégicos por los gobiernos locales y federal mientras enfrentamos el mayor número de casos desde que esto comenzara.

No sabemos qué va a ocurrir. Como siempre, pero como nunca antes.

Entre los cambios en nuestros hábitos de compra, los paseos y las trasmutaciones de la afectividad, los trastornos del sueño, la violencia con el enemigo en casa, la pérdida de los 
espacios y la ansiedad campeando entre todos y manifestándose de acuerdo a la circunstancia de cada uno, la ciencia parece haber recuperado un poco del terreno perdido. A pesar de las curas milagrosas y las historias paralelas, a pesar de la política y la empresa, parece que la confianza en el trabajo científico podría haber ganado un pasito y ahí nos tiene esperando una vacuna, censurando las explicaciones apresuradas, tratando de analizar y modelar a veces fallidamente lo sucedido. Al final, igual es otra de esos cuentos de hadas que nos dan tranquilidadante la incertidumbre, ese limbo en el que nos abandonamos, que intentamos sobrellevar mirando hacia otro tiempo, imaginando el futuro que será o que podría ser o bien, añorando lo perdido y fustigándonos por lo que hicimos mal como Humanidad. Ante esto, creo que el esfuerzo consistente y a veces irracional por recuperar la sensación de normalidad nos seguirá acompañando, como me veo acompañado por ello y miro a mi alrededor virtual para encontrar sus ecos. Al final, todo es nuevo y seguimos sin saber, tratando de descifrar los cuadros que vemos a través de los cristales de las casas, los teléfonos y las computadoras. 